\title{
Association between sedentary behaviour and socioeconomic factors, diet and lifestyle among the Balearic Islands adolescents
}

\author{
Maria del Mar Bibiloni ${ }^{1}$, Jordi Pich ${ }^{1}$, Alfredo Córdova ${ }^{2}$, Antoni Pons ${ }^{1}$ and Josep A Tur ${ }^{1 *}$
}

\begin{abstract}
Background: Many different factors influenced food habits and physical activity patterns of adolescents in a complex interactive way. The aim of this study was to assess association between sedentary behaviour and socioeconomic factors, diet and lifestyle among the Balearic Islands adolescents.
\end{abstract}

Methods: A cross-sectional survey ( $n=1961 ; 12-17$ years old) was carried out. Physical activity was assessed using the International Physical Activity Questionnaire for adolescents (IPAQ-A). Sedentary behaviour was defined as $<300 \mathrm{~min} /$ week of moderate and vigorous physical activity. Anthropometric measurements, body image, socio-economic and lifestyle determinants, food consumption, and adherence to the Mediterranean diet were assessed.

Results: The prevalence of sedentary behaviour was $37.1 \%$ (22.0\% boys, 50.8\% girls). Active boys consumed frequently breakfast cereals and fresh fruit; active girls yogurt, cheese, breakfast cereals, and fresh fruit; and sedentary girls high fat foods and soft drinks. Sedentary behaviour of girls was directly associated to age, and time spent on media screen and homework, and inversely related to adherence to Mediterranean diet, and body composition. Sedentary behaviour of boys was inversely related to adherence to the Mediterranean diet, and the desire to remain the same weight.

Conclusions: The prevalence of sedentary behaviour among Balearic Islands adolescents is high, mainly among girls. Age, sex, parental educational and profession levels, body size dissatisfaction, and poor quality diet are important factors of physical activity practice among adolescents.

\section{Background}

Adolescence is a transitional stage and many changes take place at physiologic and behavioural levels, representing an important life stage for the development of healthy nutrition [1] and physical activity behaviours. Many different factors influenced food habits and physical activity patterns in a complex interactive way [2]. Socio-cultural factors as parental occupational status, maternal level of education, cultural and/or religious habits, and the role of family and patterns of beauty are factors that have a strong influence on eating habits [3] and physical activity in adolescents [4-7].

\footnotetext{
*Correspondence: pep.tur@uib.es

'Research Group on Community Nutrition and Oxidative Stress, University of Balearic Islands, Guillem Colom Bldg, Campus, E-07122 Palma de Mallorca, Spain

Full list of author information is available at the end of the article
}

Reductions in physical activity in youth as a result of adopt a major inactive lifestyle, increasing time spent watching television, playing video games and Internet over the past two decades are believed to explain part of the rising prevalence of obesity in children and adolescents [8-10]. The prevalence of overweight and obesity among children and adolescents has risen greatly worldwide [8], with current estimates suggesting that around $30 \%$ of boys and $25 \%$ of girls in the Balearic Islands are overweight or obese [11]. However, physical inactivity has been related not only to obesity but also to the associated morbidity and non transmittable chronic diseases [12], being one of the major importance in public health because is highly prevalent $[13,14]$.

Cohort studies have evidenced that physical inactivity during childhood and/or adolescence tends to continue into adulthood, becoming difficult to change $[7,15]$. 
However, among environmental factors of obesity and risk of disease the lack of regular physical activity is potentially modifiable [13] and programs to stimulate physical activities in this age range should be a priority for public health policies and a focus for teachers [7]. Therefore, the aim of this study was to assess association between sedentary behaviour and socioeconomic factors, diet and lifestyle among Balearic Islands adolescents.

\section{Methods}

\section{Study design}

The study is a population-based cross-sectional nutritional survey carried out (2007-2008) in the Balearic Islands (Spain), a Mediterranean region.

\section{Selection of participants, recruitment and approval}

A multicenter study was performed on Balearic Islands' adolescents aged 12-17 years. The population was selected by means of a multiple-step, simple random sampling, taking into account first the location (Palma de Mallorca, Calvià, Inca, Manacor, Maó, Eivissa, Llucmajor, Santa Margalida, S’Arenal, Sant Jordi de Ses Salines) and then by random assignment of the schools within each city. Sample size was stratified by age and sex. The socio-economic variable was considered to be associated to geographical location and type of school. As the selection of schools was done by random selection and fulfilling quota, this variable was also considered to be randomly assigned.

To calculate the number of adolescents to be included in the study in order to guarantee a representative sample of the whole Balearic Islands, we selected the variable with the greatest variance for this age group from the data published in the literature at the time the study was planned; that was BMI [16]. The sampling was determined for the distribution of this variable; the CI was established at $95 \%$ with an error \pm 0.25 . The established number of subjects was 2400. The total number of subjects was uniformly distributed in the cities and proportionally distributed by sex and age group. Exclusion criteria were: type 2 diabetes, pregnancy, alcohol or drug abuse, and non-directly related nutritional medical conditions.

The sample was oversized to prevent loss of information and as necessary to do the fieldwork in complete classrooms. In each school, classrooms were randomly selected among those of the same grade or level, and all the adolescents of one classroom were proposed to participate in the survey. A letter about the nature and purpose of the study informed parents or legal tutors. After receiving their written consent, the adolescents were considered for inclusion in the study. All responses of questionnaires were filled in by adolescents. After finishing the field study, the adolescents who did not fulfil the inclusion criteria were excluded. Finally, the sample was adjusted by a weight factor in order to balance the sample in accordance to the distribution of the Balearic Islands' population and to guarantee the representativeness of each of the groups, already defined by the previously mentioned factors (age and sex). The final number of subjects included in the study was 1961 adolescents (82\% participation). The reasons to not participate were (a) the subject declined to be interviewed, and (b) the parents did not authorize the interview.

This study was conducted according to the guidelines laid down in the Declaration of Helsinki, and all procedures involving human subjects were approved by the Balearic Islands' Ethics Committee (Palma de Mallorca, Spain).

\section{Anthropometry measurements}

Height was determined using a mobile anthropometer (Kawe 44444, Asperg, Germany) to the nearest millimetre, with the subject's head in the Frankfurt plane. Body weight was determined to the nearest $100 \mathrm{~g}$ using a digital scale (Tefal, sc9210, Rumilly, France). The subjects were weighed in bare feet and light underwear. Waist circumference (WC) and hip circumference (HC) were measured using a non-stretchable measuring tape (Kawe, 43972, Asperg, Germany). The subjects were asked to stand erect in a relaxed position with both feet together on a flat surface. WC was measured as the smallest horizontal girth between the costal margins and the iliac crests at minimal respiration. Measurements were made to the nearest $0.1 \mathrm{~cm}$. $\mathrm{HC}$ was taken as the greatest circumference at the level of greater trochanters (the widest portion of the hip) on both sides. Measurements were made to the nearest $0.1 \mathrm{~cm}$. Triceps and subscapular skinfold thickness (ST) were measured at the right side of the using a Holtain skinfold caliper (Tanner/Whitehouse, Crosswell, Crymych, UK), and the mean of three measurements was used. Body fat percentage $(\% \mathrm{BF})$ was measured from triceps and subscapular ST according to Slaughter et al. [17]. This equation has been proposed as the most accurate for estimation of \%BF from ST in this particular population of adolescents [18]. Height and weight measures were used to calculate body mass index (BMI, $\mathrm{kg} / \mathrm{m}^{2}$ ) and $\mathrm{WC}$ and height were used to calculate waist-to-height ratio (WHtR). \%BF and height were used to calculate fat mass index (FMI; $\mathrm{kg} / \mathrm{m}^{2}$ ).

\section{Defining overweight and obesity}

Adolescents were classified into three groups as follows: (i) not at risk (BMI for age and sex $<$ P97, and FMI $<4.58 \mathrm{~kg} / \mathrm{m}^{2}$ in boys, FMI $<7.76 \mathrm{~kg} / \mathrm{m}^{2}$ in girls); (ii) overweight (BMI for age and sex $<$ P97, and FMI $\geq 4.58 \mathrm{~kg} / \mathrm{m}^{2}$ in boys, FMI $\geq 7.76 \mathrm{~kg} / \mathrm{m}^{2}$ in girls); and (iii) obesity (BMI for age and sex $\geq$ P97, and 
$F M I \geq 4.58 \mathrm{~kg} / \mathrm{m}^{2}$ in boys, $\mathrm{FMI} \geq 7.76 \mathrm{~kg} / \mathrm{m}^{2}$ in girls). The variable was labeled as 'body composition' [19]. Age- and sex-specific BMI cut-offs were used according to the International Obesity Task Force and Cole et al. definitions [20], and FMI cut-offs according to AlveroCruz et al. [21] criteria for adolescents: $4.58 \mathrm{~kg} / \mathrm{m}^{2}$ in boys and $7.76 \mathrm{~kg} / \mathrm{m}^{2}$ in girls, as the limit between normal-fat and overfat.

\section{Body image}

Perceived body image was measured using the Stunkard scale [22], which consists of silhouette drawings ranging from 1 to 9 with monotonic increments in overweight percentage where 1 is the leanest and 9 is the heaviest. Separate figures for boys and girls were used. Participants were asked to identify of the 9 body figures: (a) 'Which silhouette looks most like yourself?' and (b) 'Which silhouette would you like to look like?' The difference between perceived body image and desired body image was used to determine the level of dissatisfaction with current body image. Values other than zero represent dissatisfaction with perceived body image. A positive value was indicative of the participant's desire to be thinner than his/her perceived current size, while a negative value reflected the participant's desire to be thicker than his/her current perceived size [23,24].

\section{Assessment of physical activity}

Physical activity was evaluated according to the guidelines for data processing and analysis of the international physical activity questionnaire (IPAQ) [25] in the short form, and its specific modification for adolescents (IPAQ-A) [26]. The specific types of activity assessed were walking, and moderate (i.e. physical activity at school), and vigorous (i.e. sport practice) activity. According to the AVENA (Food and Assessment of Nutritional Status of Adolescents) study [27], the questionnaire also included information on television (TV) viewing, computer use and video games and homework in $\mathrm{h} / \mathrm{d}$, and usual sleep duration to the nearest $10 \mathrm{~min}$. According to recent reports of physical activity for adolescents $[7,28]$, sedentary behaviour was established with a cut-off level of $300 \mathrm{~min}$ of moderate/vigorous physical activity (MVPA) per week.

\section{Socioeconomic factors}

Socio-demographic factors were recorded using a questionnaire that included age group; parental education level (according to years and type of education: low, $<6$ years; medium, $6-12$ years; high, $>12$ years); and parental profession level (based on the occupation of parents and classified as low, medium and high, according to the Spanish Society of Epidemiology [29]. The number of daily meals and snacks was calculated from the total eating occasions that participants declared among the following: breakfast; mid-morning snack; lunch; midafternoon snack; dinner; before going to sleep; others. According to previous studies that found an inverse relationship between eating frequency and BMI [11], three groups of eating frequency were considered: $\leq 3,4$ and $\geq 5$ times/d.

\section{Dietary assessment}

A semi-quantitative food-frequency questionnaire (FFQ) previously validated [30] was used. The FFQ, which asked the subject to recall average use over the past year, consisted of 145 items (118 of the original validated FFQ plus the most characteristic Balearic Islands foods in order to make easy the interviewee answer), and arranged by food type and meal pattern. Edible fractions of foods were recorded in the database. Frequency of food consumption was based on times that food items were consumed (per day, week or month). Consumption $<1 /$ month was considered no consumption. The period of consumption of seasonal items was also considered. The 145 foods items from the FFQ were collapsed to twenty-nine food groups, which may have practical importance in daily diet and clinical practice among Mediterranean younger [31,32].

\section{Adherence to the Mediterranean diet}

The degree of adherence to the Mediterranean diet was evaluated using the KIDMED index (Mediterranean diet quality index for children and adolescents), described elsewhere [33]. Based on the given answers, the test classified individuals according to the quality of the Mediterranean diet categorized as: high, medium or poor.

\section{Statistics}

Analyses were performed with Statistical Package for the Social Sciences version 19.0 (SPSS, Inc., Chicago, IL, USA). All tests were stratified by sex. Significant differences in prevalence were calculated by means of $\chi^{2}$. Differences between means were tested using ANOVA. Logistic regression models with the calculations of corresponding adjusted odds ratios and 95\% confidence intervals were used to examine possible differences between those adolescents who were sedentary or active. Univariate analysis was first carried out for all the sociodemographic and lifestyle variables that could be associated with sedentary behaviour. Any factor that was significantly associated was considered as a candidate for the multivariate model. Multiple logistic regression analyses were used to simultaneously examine the effect of different socio-demographic and lifestyle variables on the prevalence of sedentary behaviour. Multiple logistic regression analyses were also used to simultaneously examine the association between sedentary behaviour 
Table 1 Physical activity and lifestyle of Balearic Islands adolescents stratified by sex and age

\begin{tabular}{|c|c|c|c|c|c|c|}
\hline & & \multicolumn{5}{|l|}{ Age group } \\
\hline & & Total & $12-13$ & $14-15$ & $16-17$ & $P$ \\
\hline \multirow[t]{24}{*}{ Boys } & $n$ & 939 & 240 & 445 & 254 & \\
\hline & Physical activity ${ }^{1}(\%) \dagger$ & & & & & \\
\hline & Inactive & 22.0 & 17.6 & 23.2 & 24.0 & NS \\
\hline & Active & 78.0 & 82.4 & 76.8 & 76.0 & \\
\hline & Physical activity practice & & & & & \\
\hline & Moderate & & & & & \\
\hline & Did not engage (\%)† & 8.9 & 7.2 & 7.6 & 12.8 & * \\
\hline & Mean duration (min/week) & $215.1 \pm 250.5$ & $264.9 \pm 330.2^{a}$ & $192.6 \pm 200.7^{a}$ & $208.4 \pm 237.7$ & $* *$ \\
\hline & Time spent (\% total)† & $35.7 \pm 28.6$ & $35.2 \pm 24.6$ & $35.9 \pm 27.3$ & $35.7 \pm 28.6$ & NS \\
\hline & Vigorous & & & & & \\
\hline & Did not engage (\%)† & 11.0 & 8.0 & 11.1 & 13.6 & NS \\
\hline & Mean duration (min/week) & $502.8 \pm 401.4$ & $558.7 \pm 454.2$ & $486.6 \pm 387.3$ & $477.8 \pm 367.6$ & NS \\
\hline & Time spent (\%)† & $64.3 \pm 27.0$ & $64.8 \pm 24.6$ & $64.1 \pm 27.3$ & $64.3 \pm 28.6$ & NS \\
\hline & Media-screen time (\%)† & & & & & \\
\hline & $<2 \mathrm{~h} / \mathrm{d}$ & 17.6 & 21.2 & 16.0 & 17.1 & * \\
\hline & $2-4 \mathrm{~h} / \mathrm{d}$ & 42.6 & 47.7 & 41.1 & 40.2 & \\
\hline & $\geq 4 \mathrm{~h} / \mathrm{d}$ & 39.8 & 31.1 & 42.8 & 42.7 & \\
\hline & Homework time (\%)† & & & & & \\
\hline & $<1 \mathrm{~h} / \mathrm{d}$ & 16.3 & 13.8 & 19.1 & 13.8 & NS \\
\hline & $1-3 \mathrm{~h} / \mathrm{d}$ & 69.7 & 69.7 & 69.3 & 70.4 & \\
\hline & $\geq 3 \mathrm{~h} / \mathrm{d}$ & 14.0 & 16.5 & 11.6 & 15.8 & \\
\hline & Sleep time $(\%) \dagger$ & & & & & \\
\hline & $<7 \mathrm{~h} / \mathrm{d}$ & 9.5 & 7.1 & 9.2 & 12.2 & NS \\
\hline & $\geq 7 \mathrm{~h} / \mathrm{d}$ & 90.5 & 92.9 & 90.8 & 87.8 & \\
\hline \multirow[t]{17}{*}{ Girls } & $n$ & 1022 & 255 & 503 & 264 & \\
\hline & Physical activity ${ }^{1}(\%) \dagger$ & & & & & \\
\hline & Inactive & 50.8 & 41.4 & 51.9 & 57.3 & ** \\
\hline & Active & 49.2 & 58.6 & 48.1 & 42.7 & \\
\hline & Physical activity practice & & & & & \\
\hline & Moderate & & & & & \\
\hline & Did not engage (\%)† & 12.7 & 7.9 & 11.0 & 20.0 & $* * *$ \\
\hline & Mean duration (min/week) $\$$ & $169.1 \pm 165.7$ & $188.5 \pm 210.5$ & $164.1 \pm 147.1$ & $158.8 \pm 146.1$ & $*$ \\
\hline & Time spent (\% total)† & $50.4 \pm 33.7$ & $47.2 \pm 31.6$ & $52.0 \pm 33.7$ & $50.6 \pm 35.8$ & NS \\
\hline & Vigorous & & & & & \\
\hline & Did not engage (\%)† & 28.4 & 20.3 & 29.4 & 33.8 & $* *$ \\
\hline & Mean duration (min/week) $\$$ & $354.3 \pm 356.2$ & $422.6 \pm 470.4^{a, b}$ & $338.9 \pm 313.8^{\mathrm{a}}$ & $308.5 \pm 267.2^{b}$ & ** \\
\hline & Time spent (\%)† & $49.6 \pm 33.7$ & $52.8 \pm 31.6$ & $48.0 \pm 33.7$ & $49.4 \pm 35.8$ & NS \\
\hline & Media-screen time (\%)† & & & & & \\
\hline & $<2 \mathrm{~h} / \mathrm{d}$ & 21.2 & 28.0 & 17.5 & 21.6 & ** \\
\hline & $2-4 \mathrm{~h} / \mathrm{d}$ & 38.7 & 41.0 & 36.3 & 40.9 & \\
\hline & $\geq 4 \mathrm{~h} / \mathrm{d}$ & 40.2 & 31.0 & 46.2 & 37.5 & \\
\hline
\end{tabular}


Table 1 Physical activity and lifestyle of Balearic Islands adolescents stratified by sex and age (Continued)

\begin{tabular}{|c|c|c|c|c|c|}
\hline \multicolumn{6}{|c|}{ Homework time (\%)† } \\
\hline$<1 \mathrm{~h} / \mathrm{d}$ & 8.3 & 8.9 & 10.0 & 4.3 & $* *$ \\
\hline $1-3 \mathrm{~h} / \mathrm{d}$ & 66.0 & 68.5 & 67.6 & 60.9 & \\
\hline$\geq 3 \mathrm{~h} / \mathrm{d}$ & 25.7 & 22.6 & 22.4 & 34.8 & \\
\hline \multicolumn{6}{|c|}{ Sleep time (\%)† } \\
\hline$<7 \mathrm{~h} / \mathrm{d}$ & 8.9 & 3.1 & 9.7 & 12.9 & $* * *$ \\
\hline$\geq 7 \mathrm{~h} / \mathrm{d}$ & 91.1 & 96.9 & 90.3 & 87.1 & \\
\hline
\end{tabular}

${ }^{1}$ Physical inactivity was defined as $<300 \mathrm{~min} /$ week of moderate and vigorous physical activity [7]. Values are mean \pm SD and\%. Significant differences between age groups by: $+\chi^{2}$ and $\ddagger$ ANOVA: ${ }^{*} p<0.05 ;{ }^{* *} p<0.01 ;{ }^{* * *} p<0.001$. NS: not significant. Significant differences between pairs of means by Bonferroni's post-hoc test $(P<0.05):{ }^{\mathrm{a}} 12-13^{\prime}$ vs. '14-15'; ${ }^{b} 12-13^{\prime}$ vs. '16-17'.

and dietary patterns adjusted by potential confounders (e.g. age, parental education level, and parental profession level, body composition, number of daily meals and snacks, desire for weight change, and energy intake). Level of significance for acceptance was $P<0.05$.

\section{Results}

Table 1 shows physical activity and lifestyle of Balearic Islands adolescents stratified by sex and age. Sedentary behaviour among adolescents was $37.1 \%$. Boys were more active and spend more weekly time in both moderate and vigorous physical activity than girls, and boys were devoted more weekly time to vigorous physical activity (64\%) than girls (50\%). Girls (50.8\%) showed higher sedentary behaviour than boys $(22.0 \%)$, and this prevalence increased with age, whereas time devoted to vigorous physical activity decreased with age; the physical activity practice decreases annually $1.3 \%$ (boys) and $3.2 \%$ (girls). Time devoted to media screen was higher among 14-y.o. boys and girls; and time spent on homework, and sleep time increased with age in girls, but not in boys.

Table 2 shows anthropometric characteristics of Balearic Islands adolescents according to physical activity practice and stratified by sex. Sedentary boys showed higher adiposity (measured by means of BMI, WC, HC, TSF, SCSF,\%BF and WHtR), and sedentary girls showed lower weight, BMI and $\mathrm{HC}$ than their active counterparts.

Food consumption among active and sedentary Balearic Islands adolescents is showed in Table 3. Active boys consumed frequently breakfast cereals and fresh fruit than their sedentary peers. Active girls consumed frequently yogurt and cheese, breakfast cereals, and fresh fruit than their sedentary counterparts. Sedentary girls consumed more frequently high fat foods and soft drinks than their active peers.

Table 2 Anthropometric characteristics of Balearic Islands adolescents, according to physical activity practice and stratified by sex

\begin{tabular}{|c|c|c|c|c|c|c|}
\hline & & pys & & & irls & \\
\hline & Sedentary adolescents & Active adolescents & $P$ & Sedentary adolescents & Active adolescents & $P$ \\
\hline$n$ & 207 & 732 & & 519 & 503 & \\
\hline$\%$ & 22.0 & 78.0 & & 50.8 & 49.2 & \\
\hline Weight (kg) & $65.1 \pm 13.1$ & $63.2 \pm 13.0$ & NS & $56.1 \pm 11.0$ & $57.8 \pm 11.1$ & $*$ \\
\hline Height (cm) & $169.5 \pm 8.6$ & $170.3 \pm 8.7$ & NS & $161.0 \pm 6.6$ & $160.8 \pm 6.6$ & NS \\
\hline BMI $\left(\mathrm{kg} / \mathrm{m}^{2}\right)$ & $22.5 \pm 3.8$ & $21.7 \pm 3.8$ & $* *$ & $21.6 \pm 4.0$ & $22.3 \pm 3.8$ & ** \\
\hline WC $(\mathrm{cm})$ & $74.7 \pm 8.6$ & $72.9 \pm 8.4$ & * & $67.8 \pm 8.2$ & $68.6 \pm 8.1$ & NS \\
\hline $\mathrm{HC}(\mathrm{cm})$ & $93.6 \pm 9.9$ & $91.6 \pm 10.0$ & * & $93.5 \pm 9.9$ & $95.0 \pm 9.8$ & $*$ \\
\hline TSCF (mm) & $11.7 \pm 5.1$ & $10.5 \pm 5.1$ & $* *$ & $15.3 \pm 5.3$ & $15.2 \pm 5.3$ & NS \\
\hline SCSF (mm) & $12.1 \pm 3.2$ & $10.1 \pm 5.9$ & $* * *$ & $12.9 \pm 6.0$ & $13.1 \pm 6.0$ & NS \\
\hline $\mathrm{BF}(\%)$ & $19.2 \pm 4.6$ & $16.5 \pm 8.4$ & $* * *$ & $24.2 \pm 6.4$ & $24.1 \pm 6.4$ & NS \\
\hline FMl & $4.7 \pm 2.8$ & $3.8 \pm 2.8$ & $* * *$ & $5.4 \pm 2.2$ & $5.6 \pm 2.3$ & NS \\
\hline WHtR & $0.5 \pm 0.06$ & $0.4 \pm 0.05$ & $* *$ & $0.4 \pm 0.04$ & $0.4 \pm 0.04$ & NS \\
\hline
\end{tabular}

Abbreviations: BMI, body mass index; WC, waist circumference; HC, hip circumference; TSCF, tricipital skinfold thickness; SCSF, subscapular skinfold thickness; BF, body fat; FMI, fat mass index; WHtR, waist-to-height ratio.

Values are mean \pm SD. Significant differences between sedentary and active adolescents by ANCOVA adjusted for age, parental profession level, parental education level, number of daily meals \& snacks, and adherence to the Mediterranean diet.

${ }^{*} p<0.05 ;{ }^{* *} p<0.01 ;{ }^{* * *} p<0.001$. NS: not significant. 
Table 3 Food consumption among active and sedentary Balearic Islands adolescents

\begin{tabular}{|c|c|c|c|c|}
\hline \multirow[t]{3}{*}{ Food groups } & \multirow{3}{*}{$\begin{array}{l}\text { Frequency } \\
\text { consumption }\end{array}$} & \multicolumn{3}{|c|}{ Boys } \\
\hline & & $\begin{array}{c}\text { Active } \\
\text { adolescents (\%) }\end{array}$ & $\begin{array}{c}\text { Sedentary } \\
\text { adolescents (\%) }\end{array}$ & $P$ \\
\hline & & $n=732$ & $\mathrm{n}=\mathbf{2 0 7}$ & \\
\hline
\end{tabular}

\begin{tabular}{|c|c|}
\hline \multicolumn{2}{|r|}{ Girls } \\
\hline $\begin{array}{c}\text { Active } \\
\text { adolescents (\%) }\end{array}$ & $\begin{array}{c}\text { Sedentary } \\
\text { adolescents (\%) }\end{array}$ \\
\hline$n=519$ & $\mathrm{n}=503$ \\
\hline
\end{tabular}

\section{Dairy products}

Yogurt \& cheese

\section{2}

$\geq 7$ times/week

Dairy desserts

$\geq 2$ times/week

68.4

71.5

$\geq 2$ times/week

Red meatt

Poultry \& rabbit†

$\geq 2$ times/week

53.0

15.6

Sausages

$\geq 5$ times/week

2-4 times/week

$\leq 4$ times/month

Fish \& seafood +

$\geq 2$ times/week

$\geq 2$ times/week

$\geq 2$ times/week

Legumes

Cereals, grains \& products

Breadt
Breakfast cerealst
Biscuits
Pastat
Rice dishest
Pizzat

\section{Fruits}

Fresh fruit†
Fruit juices
Canned fruit
Vegetables $†$

Vegetables $†$

Nuts $\dagger$

Potatoes \& tubercles $\dagger$

Fats

Olive oil
Others oils \& fats
High fat foods

$\geq 2$ times/week

$\geq 5$ times/week

2-4 times/week

$\leq 4$ times/month

\section{$\geq 7$ times/week}

86.5

47.1

51.3

$\geq 7$ times/week

$\geq 2$ times/week

\section{Drinks}

Soft drinks

Tea \& coffee

$\geq 5$ times/week

55.4

2-4 times/week

$\leq 4$ times/month

32.4

Alcoholic beverages

$\geq 2$ times/week

15.1

11.1

$\geq 1$ times/week $\geq 7$ times/week

$\geq 7$ times/week

$\begin{array}{ll}76.8 & 0.906 \\ 62.4 & 0.123 \\ 72.2 & 0.863\end{array}$

\section{6}

64.5

61.9

0.489

0.698

0.754

0.922

0.774

0.089

0.062

0.772

19.8

82.8

0.201

0.011

0.592

0.778

0.860

0.093

14.4

21.9

0.024

0.074

0.878

0.748

0.193

0.471

44.9

55.4

$$
82.9
$$

34.7

49.1

6.6

6.6

11.4

52.3

23.3

39.6
17.7
46.5
26.2
27.3
19.3
23.8
19.3

64.5

0.333

56.1

0.009

62.9

0.763

$\begin{array}{ll}42.8 & 0.314 \\ 21.3 & 0.171 \\ 48.1 & 0.644 \\ 21.3 & 0.086 \\ 30.6 & 0.271 \\ 14.8 & 0.071 \\ 22.2 & 0.558 \\ 18.3 & 0.685\end{array}$

81.1

0.475

26.4

0.006

44.2

0.139

0.603

0.789

7.0

0.525

12.8

22.5

0.000

45.7

0.046

3.0

0.141

13.2

0.415

25.1

0.533

32.1

0.990
45.7

0.104

0.556

0.870

0.167

0.241

33.7

0.986

0.254

0.429

0.363

$\begin{array}{ll}9.6 & 0.561\end{array}$
57.0

36.3

26.8

29.0

44.2

32.0

10.1

57.9

14.2

4.2

$\begin{array}{ll}55.0 & 0.530 \\ 37.0 & 0.829 \\ 36.8 & 0.001 \\ 29.4 & 0.905 \\ 33.8 & 0.001\end{array}$

\section{6}

10.9

44.4

18.7

5.4
0.000 0.691 0.000 0.069 0.427 
Table 3 Food consumption among active and sedentary Balearic Islands adolescents (Continued)

\begin{tabular}{|c|c|c|c|c|c|c|c|}
\hline \multicolumn{8}{|l|}{ Other foods } \\
\hline \multirow[t]{3}{*}{ Sweets } & $\geq 5$ times/week & 69.9 & 70.7 & 0.830 & 77.8 & 74.6 & 0.264 \\
\hline & 2-4 times/week & 16.4 & 13.8 & 0.408 & 12.8 & 16.2 & 0.152 \\
\hline & $\leq 4$ times/month & 13.7 & 15.5 & 0.559 & 9.4 & 9.2 & 0.921 \\
\hline \multirow[t]{3}{*}{ Chocolates } & $\geq 5$ times/week & 17.0 & 21.5 & 0.166 & 16.7 & 16.1 & 0.791 \\
\hline & 2-4 times/week & 12.2 & 13.3 & 0.697 & 10.9 & 12.2 & 0.537 \\
\hline & $\leq 4$ times/month & 70.8 & 65.2 & 0.151 & 72.4 & 71.7 & 0.825 \\
\hline
\end{tabular}

†Food consumption cut-offs [31,32]. Significant differences between active and sedentary adolescents by $x^{2}$ test.

Association between sedentary behaviour and socioeconomic factors, diet and lifestyle among the boys and girls are showed in Table 4. Univariate analysis showed that parental educational and profession levels are directly associated to sedentary behaviour in girls, and body composition to sedentary behaviour in boys (data not shown). Multivariate analysis showed that sedentary behaviour of girls was directly related to age, and time spent on media screen and homework, and inversely related to adherence to Mediterranean diet, and body composition, and that sedentary behaviour of boys was inversely related to adherence to the Mediterranean diet, and the desire to remain the same weight.

\section{Discussion}

Our study has assessed that sedentary behaviour among Balearic Islands adolescents is high (37.1\%), mainly among girls (22\% boys and $50.8 \%$ girls), but lower than those of American (55.9\%) [34], Brazilian (56.9\%) [35] and other European adolescents [36].

In our study boys were more active than girls in all age groups, and sex difference was accentuated with age for a significant declined physical activity practice in girls. Adolescence is the beginning of the decline of physical activity practice [37], which decreases annually about $2.7 \%$ among boys and $7.4 \%$ among girls between the ages of 10 and 17 [38]. Among Balearic Islands adolescents, the physical activity practice decreases annually, but less than among other adolescents. These results confirm that age and sex are important determinants of physical activity practice among adolescent population [39].

Parental educational and profession levels have been also associated with adolescents' sedentary behaviour $[7,39,40]$. In our study, the intergenerational association between parental educational and professional levels with sedentary behaviour was observed by univariate, but not multivariate, analysis in girls. Among Canary Islands' adolescents [41], father's regular physical activity in case of boys and mother's one in case of girls was positively associated with the likelihood of being active. Moreover, family usually supports engagement to physical activity practice more on boys than girls [42]. It has been also found that the access to physical activity spaces, by means of a combination of outdoor and indoor facilities, has been positively associated with the likelihood of being active in girls [41]. The access to these facilities is strongly related to the parental educational and profession level, which may explain our results.

The measurement of sedentary behaviour is not a well-developed field. We used a cut-off of $<300 \mathrm{~min} /$ week of moderate and vigorous physical activity to define sedentary behaviour in adolescents. Our results showed that sedentary behaviour was associated with spending time on use media-screen and doing homework in girls, which agrees previous findings about sex differences in sedentary behaviours $[43,44]$. Our results suggest a displacement of physical activity to sedentary pursuits in girls with age, whereas in boys the use of media-screen or homework would not necessarily affect the physical activity practice. These findings agree previous results that pointed out that the excess time accumulated in front of screens is negatively associated with MVPA in adolescents [41]. However, our study shows that time spends on media-screen and homework are useful to distinguish between active and sedentary girls.

In the present study, a significant relationship was found between body composition and physical activity practice but this association was difficult to explain for boys and girls. Thus, in agreement with previous findings reported in young people and adults $[4,45,46]$, overweight and obese boys were more sedentary than their normal weight (not at risk) counterparts; whereas obese girls were often more active than their lean peers. Although we cannot exclude the possibility that obese girls increased their physical activity as a method to selfcontrol body weight, it may be possible that obese girls over-reported their physical activity practice.

Being self-conscious about one's body size may play a role in influencing a variety of health behaviours, such as physical activity practice; however, limited research to date has been focused on the relationship of body size satisfaction and physical activity practice. Findings from 
Table 4 Association between sedentary behaviour and socioeconomic factors, diet and lifestyle among Balearic Islands adolescents

\begin{tabular}{|c|c|c|c|c|}
\hline \multirow[t]{2}{*}{ Variable } & \multicolumn{2}{|c|}{ Boys } & \multicolumn{2}{|c|}{ Girls } \\
\hline & Sedentary adolescents (\%) & Adjusted OR (95\% CI) & Sedentary adolescents & Adjusted OR \\
\hline \multicolumn{5}{|l|}{ Age group } \\
\hline 12-13 years old & 17.6 & $0.70(0.39-1.23)$ & 41.1 & $0.61(0.40-0.95)^{*}$ \\
\hline 14-15 years old & 23.2 & $0.90(0.58-1.41)$ & 51.9 & $0.91(0.64-1.29)$ \\
\hline 16-17 years old & 24.0 & 1.00 (ref.) & 57.3 & 1.00 (ref.) \\
\hline \multicolumn{5}{|l|}{ Parental education level } \\
\hline Low & 22.9 & $0.85(0.50-1.44)$ & 56.1 & $1.18(0.76-1.82)$ \\
\hline Medium & 21.4 & $1.21(0.72-2.02)$ & 51.0 & $1.18(0.78-1.78)$ \\
\hline High & 20.2 & 1.00 (ref.) & 43.5 & 1.00 (ref.) \\
\hline \multicolumn{5}{|l|}{ Parental profession level } \\
\hline Low & 21.7 & $0.73(0.37-1.42)$ & 56.8 & $1.23(0.74-2.06)$ \\
\hline Medium & 22.4 & $0.94(0.53-1.69)$ & 46.9 & $1.06(0.67-1.69)$ \\
\hline High & 20.5 & 1.00 (ref.) & 43.6 & 1.00 (ref.) \\
\hline \multicolumn{5}{|l|}{ Body composition } \\
\hline Not at risk & 19.1 & $0.61(0.28-1.36)$ & 51.6 & $2.06(1.03-4.13)^{*}$ \\
\hline Overweight & 30.9 & $0.96(0.45-2.04)$ & 59.8 & $2.91(1.29-6.57)^{*}$ \\
\hline Obesity & 37.5 & 1.00 (ref.) & 37.0 & 1.00 (ref.) \\
\hline \multicolumn{5}{|l|}{ Sleep } \\
\hline$<7 \mathrm{~h} / \mathrm{d}$ & 26.2 & $0.97(0.49-1.92)$ & 50.0 & $0.88(0.53-1.48)$ \\
\hline$\geq 7 \mathrm{~h} / \mathrm{d}$ & 21.6 & 1.00 (ref.) & 50.8 & 1.00 (ref.) \\
\hline \multicolumn{5}{|l|}{ Media-screen time } \\
\hline$<2 \mathrm{~h} / \mathrm{d}$ & 19.0 & $0.83(0.47-1.48)$ & 36.8 & $0.64(0.42-0.99)^{*}$ \\
\hline $2-4 \mathrm{~h} / \mathrm{d}$ & 20.9 & $0.92(0.60-1.42)$ & 50.1 & $0.94(0.67-1.31)^{*}$ \\
\hline$\geq 4 \mathrm{~h} / \mathrm{d}$ & 23.6 & 1.00 (ref.) & 58.7 & 1.00 (ref.) \\
\hline \multicolumn{5}{|l|}{ Homework time } \\
\hline$<1 \mathrm{~h} / \mathrm{d}$ & 28.1 & $1.67(0.83-3.37)$ & 45.5 & $0.46(0.25-0.86)^{*}$ \\
\hline $1-3 \mathrm{~h} / \mathrm{d}$ & 20.3 & $1.12(0.62-2.02)$ & 48.8 & $0.66(0.47-0.94)^{*}$ \\
\hline$\geq 3 \mathrm{~h} / \mathrm{d}$ & 22.5 & 1.00 (ref.) & 57.1 & 1.00 (ref.) \\
\hline \multicolumn{5}{|c|}{ Number of daily meals \& snacks } \\
\hline$\leq 3$ & 25.5 & $0.77(0.46-1.28)$ & 50.9 & $1.08(0.73-1.61)$ \\
\hline 4 & 20.6 & $0.70(0.44-1.12)$ & 52.7 & $1.14(0.77-1.70)$ \\
\hline$\geq 5$ & 20.2 & 1.00 (ref.) & 48.2 & 1.00 (ref.) \\
\hline \multicolumn{5}{|l|}{ KIDMED index } \\
\hline Poor -quality diet & 25.5 & $1.77(1.08-2.91)^{*}$ & 67.3 & $3.08(1.83-5.17)^{* * *}$ \\
\hline Average -quality diet & 24.5 & $0.97(0.58-1.63)$ & 52.2 & $1.57(1.10-2.23)^{*}$ \\
\hline Good -quality diet & 17.8 & 1.00 (ref.) & 39.2 & 1.00 (ref.) \\
\hline \multicolumn{5}{|l|}{ Desire for weight change } \\
\hline To be thinner & 31.3 & $0.23(0.07-1.24)$ & 50.7 & $0.77(0.40-1.45)$ \\
\hline To remain the same weight & 13.0 & $0.47(0.28-0.79)^{* *}$ & 50.1 & $0.80(0.42-1.52)$ \\
\hline To be thicker & 23.0 & 1.00 (ref.) & 53.7 & 1.00 (ref.) \\
\hline
\end{tabular}

Abbreviations: $O R$ odds ratio, $C l$, confidence interval, ref reference, KIDMED, Mediterranean Diet Quality Index; Adjusted OR: Multivariate analysis (multiple logistic regression analysis considering the simultaneous effect of all explanatory variables: age, parental education level, and parental profession level, body composition, number of daily meals and snacks, desire for weight change, and energy intake). ${ }^{*} p<0.05 ;{ }^{* *} p<0.01 ;{ }^{* * *} p<0.001$. 
the literature indicate gender differences between men and women in how they see their bodies and how this may affect their physical activity practice [47]. A previous study on adults suggested that both men and women who were unsatisfied with their body size were less likely to be regularly active than those who were satisfied $^{47}$. Similar results in boys but not in girls were observed in our study, which could be explained because boys are more likely to practice physical activity as strategy to increase body weight and muscle mass [48], while girls are more likely to meet the patterns of beauty attempting to lose weight, mainly by diets [49]. Our findings also support the suggestion [47] that a sedentary lifestyle in unsatisfied boys may also lead a selfperpetuating vicious circle of low activity.

Sedentary behaviour has been associated with food choice, and cereals, fruits and vegetables often appear in the diet of active adults and children [50]. Children who follow a healthy diet are those who might also maintain high levels of physical activity [51]. In a previous study, we found that sedentary adolescents showed the lowest adherence to the Mediterranean dietary pattern [19]. The present results showed that sedentary adolescents often consumed less cereals, and fresh fruit, whereas high fat foods appeared often in their diet.

Moreover, we have lately described two major dietary patterns in Balearic Islands adolescent population: the 'Western' and the 'Mediterranean' pattern [19]. In that study we observed that adolescents who spent $\geq 4 \mathrm{~h}$ per day on use media-screen showed higher mean intake for most of the food categories included in the 'Western' dietary pattern (e.g. dairy desserts, red meat, sausages, bread, rice dishes, fruit juices, soft drinks, high-fat foods, sweets and chocolates), whereas mean intake for yogurt \& cheese, fruit and vegetables was lower in them. Therefore, in addition to the promotion of physical activity, reductions in sedentary behaviour (i.e. media-screen time) with education programmes focused on strategies to promote healthy food choices (i.e.: following the Mediterranean diet) should be considered in nutrition education programmes for adolescents aimed at reducing risk of disease.

\section{Limitations of the study}

In the literature there are important methodological differences in instruments and cut-off points which frequently prevent comparisons among studies [52]. Questionnaires have inherent limitations, mainly because they are subjective in nature. One bias could be that all responses of questionnaires were filled in by adolescents; however, doubts were solved immediately in the classroom by interviewers. Self-report of physical activity can lead to overreport the physical activity due to a social desirability bias, and therefore the number of inactive individuals may be lower than that reported $[53,54]$, especially among children and adolescents, and also among obese [53]. Moreover, sedentary behaviours may be more difficult to remember than activities of higher intensity [55] and recall bias in self-reported sedentary behaviours have been reported among adolescents [56]. Therefore, objective methods are generally preferable in assessing dimensions of physical activity in young people [4]. An extensive range of instruments for measuring physical activity has been reported in the literature, but critical elements in the utility of an instrument to measure physical activity are to be relatively inexpensive, cause minimal inconvenience to the participant, and be able to be administered with relative ease [57]. However, in epidemiological studies, self-reporting is usually the most feasible method of assessing physical activity, especially when a high number of participants are interviewed [4].

\section{Conclusions}

The prevalence of sedentary behaviour among Balearic Islands adolescents is high, mainly among girls. Age, sex, parental educational and profession levels, dissatisfaction with body size and poor quality diet are important factors of physical activity practice among adolescent population. Adolescents are priority targets for action against obesity and related comorbidities, and they should be more aware about the health benefits of physical activity practice. Programmes to promote physical activity and reductions in sedentary behaviour among not only adolescents but also their families, combined with a Mediterranean diet, would likely result in a better healthy profile in the future.

\section{Competing interests}

The authors declare that they have no competing interests.

\section{Authors' contributions}

MMB and JAT conceived, designed, devised and supervised the study, MMB and JAT collected and supervised the samples. MMB, AC and JAT analysed the data and wrote the manuscript. AP and JAT obtained funding. All authors read and approved the final manuscript.

\section{Acknowledgements}

Funding sources: Spanish Ministry of Health and Consumption Affairs (Programme of Promotion of Biomedical Research and Health Sciences, Projects 05/1276 and 08/1259, and Red Predimed-RETIC RD06/0045/1004), Spanish Ministry of Education and Science (FPU Programme, PhD fellowship to Maria del Mar Bibiloni). The Research Group on Community Nutrition and Oxidative Stress, University of Balearic Islands belongs to the Centre Català de la Nutrició (IEC)

\section{Author details}

${ }^{1}$ Research Group on Community Nutrition and Oxidative Stress, University of Balearic Islands, Guillem Colom Bldg, Campus, E-07122 Palma de Mallorca, Spain. ${ }^{2}$ Department of Physiology and Biochemistry, School of Health Sciences, University School of Physiotherapy, University of Valladolid, Soria 42004, Spain.

Received: 23 April 2012 Accepted: 27 August 2012

Published: 30 August 2012 


\section{References}

1. McNaughton SA, Ball K, Mishra GD, Crawford DA: Dietary patterns of adolescents and risk of obesity and hypertension. J Nutr 2008, 138:364-370.

2. Aranceta J, Pérez-Rodrigo C, Ribas L, Serra-Majem L: Sociodemographic and lifestyle determinants of food patterns in Spanish children and adolescents: the enKid study. Eur J Clin Nutr 2003, 57:S40-S44.

3. Neumark-Sztainer D, Hannas PJ, Story M, Croll J, Perry C: Family meal patterns: associations with sociodemographic characteristics and improved dietary intake among adolescents. J Am Diet Assoc 2003, 103:317-322.

4. Ekelund U, Neovius M, Linné Y, Brage S, Wareham NJ, Rössner S: Associations between physical activity and fat mass in adolescents: the Stockholm Weight Development Study. Am J Clin Nutr 2005, 81:355-360.

5. Ward DS, Dowda M, Trost SG, Felton GM, Dishman RK, Pate RR: Physical activity correlates in adolescent girls who differ by weight status. Obesity (Silver Spring) 2006, 14:97-105.

6. Mota J, Fidalgo F, Silva R, Ribeiro JC, Santos R, Carvalho J, et al: Relationships between physical activity, obesity and meal frequency in adolescents. Ann Hum Biol 2008, 35:1-10.

7. Ferreira CA, Molena CA, Marques RG, Arasaki AT, Fossati F, Cícero M: Prevalence of physical inactivity and associated factors among adolescents. Rev Assoc Med Bras 2009, 55:523-528.

8. Ebbeling CB, Pawlak DB, Ludwig DS: Childhood obesity: public-health crisis, common sense cure. Lancet 2002, 360:473-482.

9. Dehghan M, Akhtar-Danesh N, Merchant AT: Childhood obesity, prevalence and prevention. Nutr J 2005, 4:24

10. Wittmeier KD, Mollard RC, Kriellaars DJ: Physical activity intensity and risk of overweight and adiposity in children. Obesity 2008, 16:415-420.

11. Bibiloni MM, Martinez E, Llull R, Juarez MD, Pons A, Tur JA: Prevalence and risk factors for obesity in Balearic Islands adolescents. Brit J Nutr 2010, 103:99-106.

12. Ball GD, McCargar L: Childhood obesity in Canada: a review of prevalence estimates and risk factors for cardiovascular diseases and type 2 diabetes. Can J Appl Physiol 2003, 28:117-140.

13. McGinnis JM, Foege WH: Actual causes of death in the United States. JAMA 1993, 270:2207-2212

14. Varo JJ, Martínez-González MA, De Irala-Estévez J, Kearney J, Gibney M, Martínez JA: Distribution and determinants of sedentary lifestyles in the European Union. Int J Epidemiol 2003, 32:138-146.

15. Aarnio M, Winter T, Peltonen J, Kujala UM, Kaprio J: Stability of leisure-time physical activity during adolescence - a longitudinal study among 16-, 17- and 18-year-old Finnish youth. Scand J Med Sci Sports 2002, 12:179-185.

16. Moreno LA, Fleta J, Mur L, Feja C, Sarría A, Bueno M: Indices of body fat distribution in Spanish children aged 4.0 to 14.9 years. J Pediatr Gastroenterol Nutr 1997, 25:175-181.

17. Slaughter MH, Lohman TG, Boileau RA, Horswill CA, Stillman RJ, van Loan $\mathrm{MD}$, et al: Skinfold equations for estimation of body fatness in children and youths. Hum Biol 1988, 60:709-723.

18. Rodríguez G, Moreno LA, Blay MG, Blay VA, Fleta J, Sarría A, et al: Body fat measurement in adolescents: comparison of skinfold thickness equations with dual-energy X-ray absorptiometry. Eur J Clin Nutr 2005, 59:1158-1166

19. Bibiloni MM, Martínez E, Llull R, Pons A, Tur JA: Western and Mediterranean dietary patterns among Balearic Island's adolescents: socio-economic and lifestyle determinants. Publ Health Nutr 2011, 15:683-692.

20. Cole TJ, Bellizzi MC, Flegal KM, Dietz WH: Establishing a standard definition for child overweight and obesity worldwide: international survey. BMJ 2000, 320:1240-1243.

21. Alvero-Cruz JR, Alvarez Carnero E, Fernández-García JC, Barrera Expósito J, Carrillo de Albornoz Gil M, Sardinha LB: Validity of body mass index and fat mass index as indicators of overweight status in Spanish adolescents: Escola Study. Med Clin (Barc) 2010, 135:8-14.

22. Stunkard AJ, Sorensen T, Schulsinger F: Use of the Danish Adoption Register for the study of obesity and thinness. Res Publ Assoc Res Nerv Ment Dis 1983, 60:115-120.

23. Bulik CM, Wade TD, Heath AC, Martin NG, Stunkard AJ, Eaves LJ: Relating body mass index to figural stimuli: population-based normative data for Caucasians. Int J Obes 2001, 25:1517-1524.
24. Baptiste-Roberts K, Gary TL, Bone LR, Hill MN, Brancati FL: Perceived body image among African Americans with type 2 diabetes. Patient Educ Couns 2006, 60:194-200.

25. International Physical Activity Questionnaire: Guidelines for Data Processing and Analysis of the International Physical Activity Questionnaire (IPAQ). 2010, http://www.ipaq.ki.es/.

26. Hagströmer M, Bergman P, De Bourdeaudhuij I, Ortega FB, Ruiz JR, Manios $Y$, et al: Concurrent validity of a modified version of the International Physical Activity Questionnaire (IPAQ-A) in European adolescents: The HELENA Study. Int J Obes 2008, 32:542-8.

27. Vicente-Rodríguez G, Rey-López JP, Martín-Matillas M, Moreno LA, Wärnberg J, Redondo C, et al: Television watching, videogames, and excess of body fat in Spanish adolescents: the AVENA study. Nutrition 2008, 24:654-62.

28. Strong WB, Malina RM, Blimkie CJR: Evidence based physical activity for school-age youth. J Pediatr 2005, 146:732-7.

29. Alvarez C, Alonso J, Domingo A, Regidor E: La medición de la clase social en ciencias de la salud. Barcelona: SG-Sociedad Española de Epidemiología; 1995.

30. Martin-Moreno JM, Boyle P, Gorgojo L, Maisonneuve P, FernandezRodriguez JC, Salvini S, et al: Development and validation of a food frequency questionnaire in Spain. Int J Epidemiol 1993, 22:512-9.

31. Lazarou C, Panagiotakos DB, Matalas AL: Level of adherence to the Mediterranean diet among children from Cyprus: the CYKIDS study. Public Health Nutr 2009, 12:991-1000.

32. Lazarou C, Panagiotakos DB, Kouta C, Matalas AL: Dietary and other lifestyle characteristics of Cypriot school children: results from the nationwide CYKIDS study. BMC Public Health Nutr 2009, 9:147.

33. Serra-Majem L, Ribas L, Ngo J, Ortega RM, García A, Pérez-Rodrigo C, et al: Food, youth and the Mediterranean diet in Spain. Development of KIDMED, Mediterranean Diet Quality Index in children and adolescents. Public Health Nutr 2004, 7:931-5.

34. Riddoch CJ, Bo Andersen L, Wedderkopp N, Harro M, Klasson-Heggebo L, Sardinha LB, et al: Physical activity levels and patterns of 9 and 15-yr-old European children. Med Sci Sports Exerc 2004, 36:86--92.

35. Hallal PC, Bertoldi AD, Goncalves H, Victora CG: Prevalence of sedentary lifestyle and associated factors in adolescents 10 to 12 years of age. Cad Saúde Pública 2006, 22:1277-87.

36. Elmadfa I: European Nutrition and Health Report 2009. Forum Nutr 2009, 62:157-201

37. Kimm SY, Glynn NW, Kriska AM, Barton BA, Kronsberg SS, Daniels SR, et al: Decline in physical activty in black girls and white girls during adolescence. N Engl J Med 2002, 347:709-15.

38. Sweeting HN: Gendered dimensions of obesity in childhood and adolescence. Nutr J 2008, 7:1-14.

39. Nader PR, Bradley RH, Houts RM, McRitchie SL, O'Brien M: Moderate-tovigorous physical activity from ages 9 to 15 years. JAMA 2008;300:295305. Erratum in. JAMA 2009, 301:2095-8.

40. La Torre G, Masala D, De Vito E, Langiano E, Capelli G, Ricciardi W: Physical Activity and Socio-Economic Status collaborative group. Extra-curricular physical activity and socioeconomic status in Italian adolescents. BMC Pub Health 2006, 6:22.

41. Serrano-Sanchez JA, Martí-Trujillo S, Lera-Navarro A, Dorado-García C, González-Henríquez JJ, Sanchís-Moysi J: Associations between screen time and physical activity among Spanish adolescents. Plos One 2011, 6:e24453.

42. Gonçalves H, Hallal PC, Amorim TC, Araújo CLP, Menezes AMB Sociocultural factors and level of physical activity in early adolescence. Rev Panam Salud Publica 2007, 22:246-53.

43. Marshall SJ, Gorely T, Biddle SJH: A descriptive epidemiology of screenbased media use in youth: a review and critique. J Adolesc 2006, 29:333-49.

44. Leatherdale ST, Wong SL: Modifiable characteristics associated with sedentary behaviours among youth. Int J Pediatr Obes 2008, 3:93-101.

45. Paul DR, Novotny JA, Rumpler WV: Effects of the interaction of sex and food intake on the relation between energy expenditure and body composition. Am J Clin Nutr 2004, 79:385-9.

46. Rush EC, Plank LD, Davies PS, Watson P, Wall CR: Body composition and physical activity in New Zealand Maori, Pacific and European children aged 5-14 years. Brit J Nutr 2003, 90:1133-9. 
47. Kruger J, Lee CD, Ainsworth BE, Macera CA: Body size satisfaction and physical activity levels among men and women. Obesity (Silver Spring) 2008, 16:1976-9

48. Khor GL, Zalilah MS, Phan YY, Ang M, Maznah B, Norimah AK: Perceptions of body image among Malaysian male and female adolescents. Singapore Med J 2009, 50:303-11.

49. Smolak L: Body image in children and adolescents: where do we go from here? Body Image 2004, 1:15-28.

50. Bellisle F: Food choice, appetite and physical activity. Pub Health Nutr 1999, 2:357-361.

51. Lazarou C, Panagiotakos DB, Matalas AL: Physical activity mediates the protective effect of the Mediterranean diet of children's obesity status: the CYKIDS study. Nutrition 2010, 26:61-7.

52. Tassitano RM, Bezerra J, Tenório MCM, Colares V, Barros MGV, Hallal PC: Atividade física em adolescentes brasileiros: uma revisão sistemática. Rev Bras Cineantropom Desempenho Hum 2007, 9:55-60.

53. Tammelin T, Näyhä S, Laitinen J, Rintamäki H, Järvelin MR: Physical activity and social status in adolescence as predictors of physical inactivity in adulthood. Prev Med 2003, 37:375-81.

54. Motl RW, McAuley E, DiStefano C: Is social desirability associated with selfreported physical activity? Prev Med 2005, 40:735-9.

55. Buchowski MS, Townsend KM, Chen KY, Acra SA, Sun M: Energy expenditure determined by self-reported physical activity is related to body fatness. Obes Res 1999, 7:23-33.

56. Affuso O, Stevens J, Catellier D, McMurray RG, Ward DS, Lytle L, et al: Validity of self-reported leisure-time sedentary behavior in adolescents. J Negat Results Biomed 2011, 10:2.

57. Hills AP: Objective instruments for measuring physical activity - an overview. In Sixth International Conference on Diet and Activity Methods Abstracts Book, SY05-01. Copenhagen. 2006. http://www.icdam.org/archives. cfm (accessed July 2012).

doi:10.1186/1471-2458-12-718

Cite this article as: Bibiloni et al: Association between sedentary behaviour and socioeconomic factors, diet and lifestyle among the Balearic Islands adolescents. BMC Public Health 2012 12:718.

\section{Submit your next manuscript to BioMed Central and take full advantage of:}

- Convenient online submission

- Thorough peer review

- No space constraints or color figure charges

- Immediate publication on acceptance

- Inclusion in PubMed, CAS, Scopus and Google Scholar

- Research which is freely available for redistribution 